\title{
Influence of pre-deformation on the precipitation of Cu-rich clusters in RPV model steel
}

\author{
Zhaozhao Tan ${ }^{1}$, Chengliang $\mathrm{Li}^{2}$, Guogang $\mathrm{Shu}^{3}$, Wei $\mathrm{Liu}^{4}$ and Qiulin $\mathrm{Li}^{1, \mathrm{a}}$ \\ ${ }^{1}$ Graduate School at Shenzhen, Tsinghua University, 518055 Shenzhen, Guangdong, China \\ ${ }^{2}$ China Nuclear Power Engineering Co., Ltd., 518031 Shenzhen, Guangdong, China \\ ${ }^{3}$ Sate Key Laboratory of Nuclear Power Safety Monitoring Technology and Equipment, China Nuclear Power Engineering Co., Ltd., \\ Shenzhen 518172, Guangdong, China \\ ${ }^{4}$ School of Material Science and Engineering, Tsinghua university, 100084 Beijing, China
}

\begin{abstract}
The effect of pre-deformation on the precipitation process of $\mathrm{Cu}$-rich clusters in reactor pressure vessels (RPV) model steel is studied. In this research, Fe-1.16wt\%Cu binary alloy is selected as RPV model steel to simulate the precipitation process of $\mathrm{Cu}$-rich clusters. The solid-solution $\mathrm{Fe}-\mathrm{Cu}$ alloys were cold rolled with pre-deformation of $0,10 \%, 25 \%, 40 \%, 60 \%$, followed by aging at $450{ }^{\circ} \mathrm{C}$ for a series time. The dislocation density, Vickers hardness and microstructure evolution of $\mathrm{Fe}-\mathrm{Cu}$ alloys after aging were determined. It is revealed that the Vickers hardness of un-deformed specimens reaches to peak hardness after aging at $450{ }^{\circ} \mathrm{C}$ for $100 \mathrm{~h}$, while the specimens with larger dislocation density reach to peak hardness faster from the Vickers hardness test result. The result of transmission electron microscopy (TEM) indicates that pre-deformation promotes the process of precipitation of $\mathrm{Cu}$-rich clusters and inhibits the growth of the $\mathrm{Cu}$-rich clusters.
\end{abstract}

\section{Introduction}

As an important protective barrier for nuclear power plants, the irradiation embrittlement of reactor pressure vessels (RPV) induced by neutron irradiation is a main factor restricting its service life. With long-term service in the environment of high temperature, high pressure and neutron irradiation, the microstructure of RPV steel will be damaged and some new crystal defects (segregation of elements or clusters of $\mathrm{Cu}, \mathrm{Mn}, \mathrm{Ni}$; stabilization substrate defects like defect clusters and dislocation; unstable matrix defects like interstitial atom and vacancy formed during cascade collision) will be induced [1-4], which will threaten the safe service of RPV. Many researchers [5-8] have done a lot of work on the irradiation embrittlement mechanism of RPV steel. The results [9] show that the precipitation of $\mathrm{Cu}$-rich clusters under neutron irradiation is an important reason for the embrittlement of RPV steel. Therefore, how to inhabit the precipitation process of $\mathrm{Cu}$-rich clusters is of great significance for improving the anti-radiation performance of RPV steel.

Due to the radiation of neutron irradiation samples, many researchers simulate the process of neutron irradiation by thermal aging. M.K. Miller [10] indicated that high number densities of $\mathrm{Cu}$-rich precipitates were observed in $\mathrm{Fe}-\mathrm{Cu}$ and $\mathrm{Fe}-\mathrm{Cu}-\mathrm{Mn}$ alloys after neutron irradiation and the number densities of the clusters were calculated to be $7 \times 10^{22} \mathrm{~m}^{-3}$ and $7 \times 10^{23} \mathrm{~m}^{-3}$ in binary and ternary alloys, respectively. Li Liu [11] revealed that the $\mathrm{Cu}$-rich precipitates were found in $\mathrm{Fe}-0.5 \mathrm{wt} \% \mathrm{Cu}-$

\footnotetext{
a Corresponding author: liql@ sz.tsinghua.edu.cn
}

$0.8 \mathrm{wt} \% \mathrm{Ni}-1.4 \mathrm{wt} \% \mathrm{Mn}$ model steel after aging for $62 \mathrm{~h}$ at $450{ }^{\circ} \mathrm{C}$ by $3 \mathrm{DAP}$ and the number density is about $1.31 \times 10^{23} \mathrm{~m}^{-3}$. The number density of $\mathrm{Cu}$ clusters after neutron irradiation and thermal aging at $450{ }^{\circ} \mathrm{C}$ is similar.

However, many researchers focus on the effect of copper content, radiation dose, radiation temperature on the cluster precipitation in RPV steels, and there is little research on the influence of microstructure of materials on the $\mathrm{Cu}$-rich cluster precipitation. Hence, this work aims to investigate the effect of pre-deformation on the process of Cu-rich clusters precipitation of RPV model steel. In this work, dislocation density of different predeformation samples, Vickers hardness, tensile properties and microstructure evolution during thermal aging were analysed. The effect of the pre-deformation on the precipitation of $\mathrm{Cu}$-rich clusters was discussed.

\section{Experimental}

In this work, $\mathrm{Fe}-1.16 \mathrm{wt} \% \mathrm{Cu}$ binary alloy is selected as RPV model steel. This material was prepared by melting of pure $\mathrm{Fe}$ and pure $\mathrm{Cu}$ in vacuum induction melting furnace and followed by hot rolling to $12 \mathrm{~mm}$ thick plate. In order to dissolve the copper into the matrix completely, the material was treated by solid solution at $850^{\circ} \mathrm{C}$ for $24 \mathrm{~h}$ and then quenched in water. The solidsolution plates were cold rolled and divided into five groups according to the deformation: un-deformed, $10 \%$ pre-deformed, $25 \%$ pre-deformed, $40 \%$ pre-deformed 
and $60 \%$ pre-deformed. The specimens of all groups were aged at $450{ }^{\circ} \mathrm{C}$ for various time, respectively.

The dislocation density of the specimen was analysed by XRD line breadth method. The specimens for XRD test were cut into $10 \times 10 \times 2 \mathrm{~mm}$ pieces followed by mechanical grinding with $\mathrm{SiC}$ sandpaper and electrolytic polishing with $10 \% \mathrm{HClO}_{4}$ and $90 \% \mathrm{C}_{2} \mathrm{H}_{5} \mathrm{OH}$ mixed solution to remove the surface stress layer. In order to make the test result more accurate, the method of step scanning was adopted.

The Vickers hardness of these specimens were measured under $300 \mathrm{~g}$ load by using an HXZ-1000 Vickers hardness testing equipment. The specimens were prepared in the same way with XRD test specimens. Each specimen was tested for five points and the average hardness value was used for the curves of hardness vs aging time.

The microstructures of specimens were studied by Transmission electron microscope (TEM). The TEM specimens were pre-thinned to $60-80 \mu \mathrm{m}$ by mechanical grinding and a $3 \mathrm{~mm}$ diameter disk was punched out using a wafer punch and finally thinned by Struers TenuPol-5 electrolytic double-jet instrument at $-20{ }^{\circ} \mathrm{C}$ and $20 \mathrm{~V}$ with $10 \% \mathrm{HClO}_{4}$ and $90 \% \mathrm{C}_{2} \mathrm{H}_{5} \mathrm{OH}$ mixed solution. The sample after double spraying was observed by TECNAI G 20 electron microscope.

\section{Results and discussion}

\subsection{Dislocation density}

Fig.1a shows the XRD profiles of all groups specimens after cold rolling and Fig.1b shows its partial enlargement. In Fig.1a, only diffraction peak of Fe can be observed and no diffraction peak of $\mathrm{Cu}$ is observed due to its little content. Fig.1b indicates that the full width at half maximum (FWHM in short) increase with the deformation, which means dislocations brought by the deformation widens the diffraction peak. Modified Williamson-Hall method [12] is used to calculate the dislocation densities of different pre-deformation samples. The diffraction profiles used for this analysis are the (110), (200), (211), (220), and (310) reflections of bcc Fe. The values of FWHM obtained from each peak are substituted into the following modified Williamson-Hall equation [13]:

$$
\Delta \mathrm{K}=\alpha / \mathrm{D}+\left(\mathrm{BM}^{2}\right)^{1 / 2} \rho^{1 / 2}\left(\mathrm{KC}^{1 / 2}\right)+\mathrm{O}\left(\mathrm{K}^{2} \mathrm{C}\right)
$$
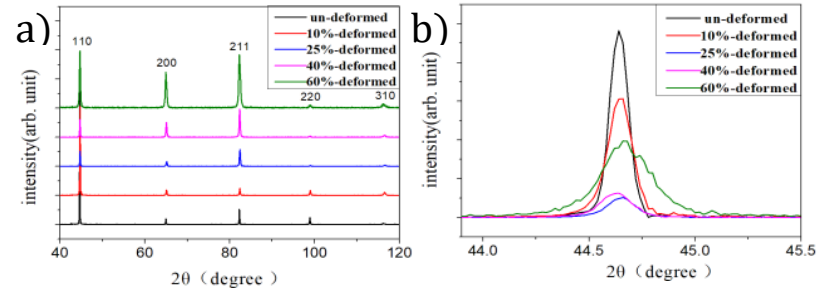

Figure 1. XRD patterns obtained from different deformation $\mathrm{Fe}-\mathrm{Cu}$ alloy (a) full spectrum; (b) partial enlargement.

where $K=2 \sin \theta / \lambda$ and $\Delta K=(\Delta 2 \theta) \cdot \cos (\theta) / \lambda,(2 \theta)$ is the FWHM of diffraction peak, $\lambda$ is the wavelength of $X$ rays. The FWHM of different diffraction angles can be obtained from the XRD pattern, and the values of dislocation density can be calculated by plotting $\Delta \mathrm{K} \sim$ $\mathrm{K} \cdot \mathrm{C}^{1 / 2}$. The dislocation density values calculated by Williamson-Hall method are shown in Table 1. From Table 1, it can be found that the dislocation density for un-deformed sample is $0.39 \times 10^{14} \mathrm{~m}^{-2}$, which is similar to the data reported in the literature for approximate material [13]. The value increase with pre-deformation rapidly, and reach to about $1.75 \times 10^{14} \mathrm{~m}^{-2}$ for the sample with $60 \%$ pre-deformed.

Table 1. The dislocation density values of different predeformation samples.

\begin{tabular}{cccccc}
\hline $\begin{array}{c}\text { Pre-deformation } \\
(\%)\end{array}$ & 0 & 10 & 25 & 40 & 60 \\
\hline $\begin{array}{c}\text { Dislocation } \\
\text { density }\left(10^{14} \mathrm{~m}^{-2}\right)\end{array}$ & 0.39 & 0.82 & 1.20 & 1.36 & 1.75 \\
\hline
\end{tabular}

\subsection{Vickers hardness evaluation during aging}

Figure 2 shows the Vickers hardness vs aging time of different deformation $\mathrm{Fe}-\mathrm{Cu}$ alloys. For all groups specimens, the Vickers hardness values increase and then decrease with the aging time. During aging, Vickers hardness increases by precipitation enhanced corresponding to the process that copper precipitates from the matrix. $\mathrm{Cu}$ is a very common alloying element in steels. The $\mathrm{Cu}$ solid-solubilized at high temperature is easily precipitated during low-temperature aging to produce precipitation strengthening, which increases the strength of the steel [14]. After reaching to peak hardness, the value of Vickers hardness decrease indicates the occurrence of over aging [15].

However, the aging time of peak hardness is quite different (Fig.2): HV 203.8 at $100 \mathrm{~h}$ for un-deformation sample, HV 207.4 at $100 \mathrm{~h}$ for $10 \%$ pre-deformation sample, HV 217.2 at $75 \mathrm{~h}$ for $25 \%$ pre-deformation sample, HV 227 at $75 \mathrm{~h}$ for $40 \%$ pre-deformation sample and HV 256.6 at $25 \mathrm{~h}$ for $60 \%$ pre-deformation sample. Obviously, large deformation, resulting in high dislocation density, leads to higher hardness because of work hardening effect. In addition, the time of peak hardness occurrence becomes earlier with the increase of pre-deformation, which means pre-deformation promotes the aging process. The reason is discussed later. The dislocation density increases with the deformation, thus energy is stored around dislocation line [16], which promotes the nucleation and growth of $\mathrm{Cu}$-rich clusters [17]. In addition, the diffusion of $\mathrm{Cu}$ atoms in the $\mathrm{Fe}$ matrix is pretty hard due to low self-diffusion coefficient of $\mathrm{Cu}$, while the dislocations in the pre-deformed samples provide fast diffusion channels for the $\mathrm{Cu}$ atoms that close to the dislocation line [18], resulting in a faster process of the $\mathrm{Cu}$-rich clusters forming. 


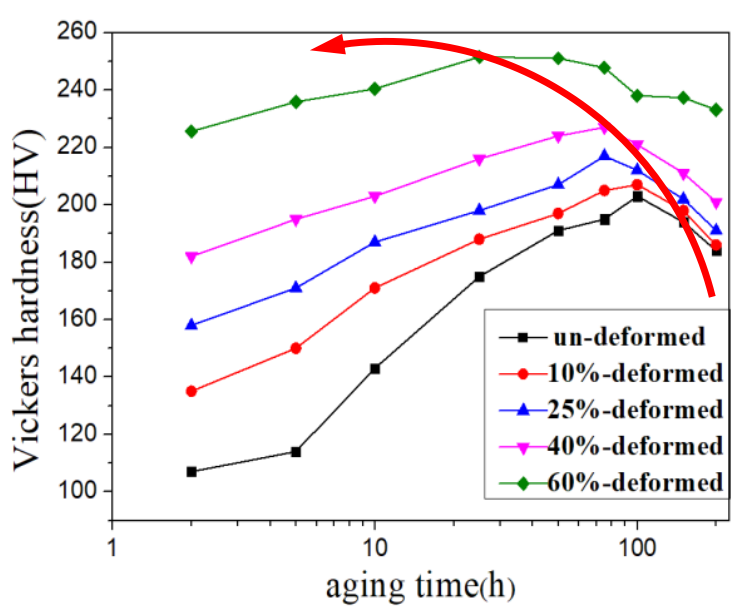

Figure 2. Vickers hardness vs aging time for un-deformed and pre-deformed $\mathrm{Fe}-\mathrm{Cu}$ alloys.

\subsection{Micro-structure evolution during aging}

Fig. 3a shows the TEM images of solid-solution state Fe$\mathrm{Cu}$ alloy un-deformed. It is obvious that $\mathrm{Cu}$ is basically dissolved into the matrix after solution at $850{ }^{\circ} \mathrm{C}$ for $24 \mathrm{~h}$. In fact, the solid solubility of $\mathrm{Cu}$ in $\alpha$-Fe can be calculated by following formula [19]:

$$
\log (\operatorname{mass} \% \mathrm{Cu})=4.335-(4499 / \mathrm{T})
$$

According to Eq. (2), the solid solubility of $\mathrm{Cu}$ in $\alpha-\mathrm{Fe}$ at $850{ }^{\circ} \mathrm{C}$ is about $2.13 \mathrm{wt} \%$, which is higher than the $1.16 \mathrm{wt} \%$ used in this work. In addition, the solid solubility of $\mathrm{Cu}$ in $\alpha-\mathrm{Fe}$ at $450{ }^{\circ} \mathrm{C}$ is about $0.01 \mathrm{wt} \%$ calculated by Eq. (2), so the $\mathrm{Cu}$ tends to separate from matrix during aging at $450{ }^{\circ} \mathrm{C}$ mightily. Fig. $3 \mathrm{~b}$ shows a typical TEM image of $\mathrm{Cu}$ cluster of $25 \%$ pre-deformed $\mathrm{Fe}-\mathrm{Cu}$ sample after aging at $450{ }^{\circ} \mathrm{C}$ for $50 \mathrm{~h}$. The size of this cluster is about $13 \mathrm{~nm}$. Fig. 3c shows the EDS result of the $\mathrm{Cu}$-rich cluster in Fig. $3 \mathrm{~b}$, which demonstrates that the $\mathrm{Cu}$-rich cluster contains about $9.8 \mathrm{wt} \% \mathrm{Cu}$, which is much higher than the value of matrix. So it can be regarded as a $\mathrm{Cu}$-rich cluster [20].
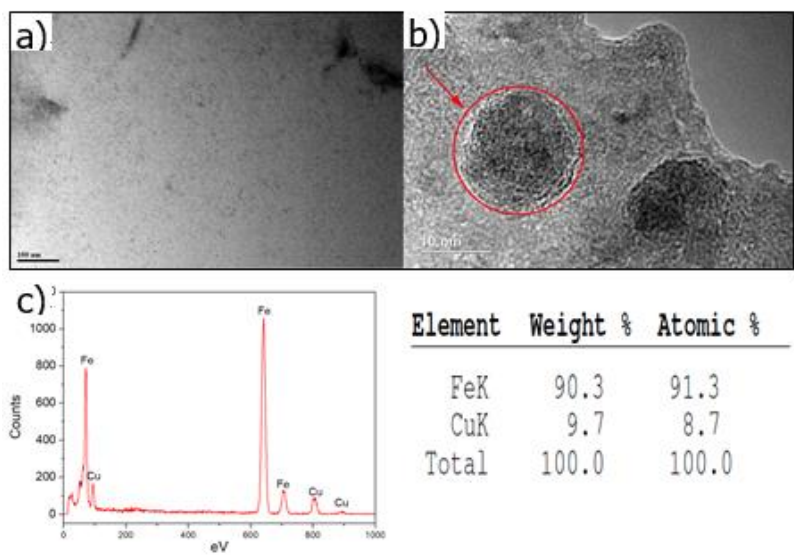

\begin{tabular}{rrc} 
Element & Weight $f$ & Atomic $f$ \\
\hline FeK & 90.3 & 91.3 \\
CuK & 9.7 & 8.7 \\
Total & 100.0 & 100.0
\end{tabular}

Figure 3. (a) TEM images of solid-solution state $\mathrm{Fe}-\mathrm{Cu}$ alloy un-deformed; (b) a typical TEM image of $\mathrm{Cu}$ cluster; (c) the EDS result of the $\mathrm{Cu}$-rich cluster.

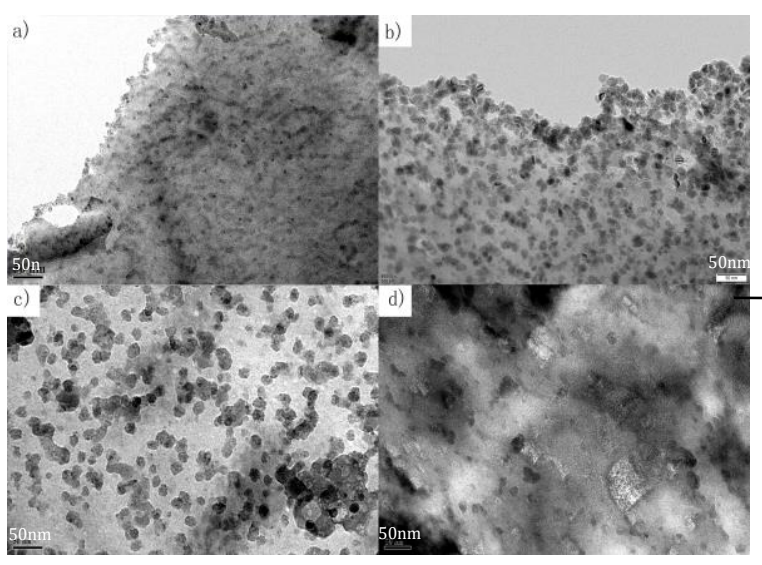

Figure 4.TEM images of $\mathrm{Fe}-\mathrm{Cu}$ alloy un-deformed aged at $450{ }^{\circ} \mathrm{C}$ for: (a) $10 \mathrm{~h}$; (b) $50 \mathrm{~h}$; (c) $100 \mathrm{~h}$; (d) $150 \mathrm{~h}$.
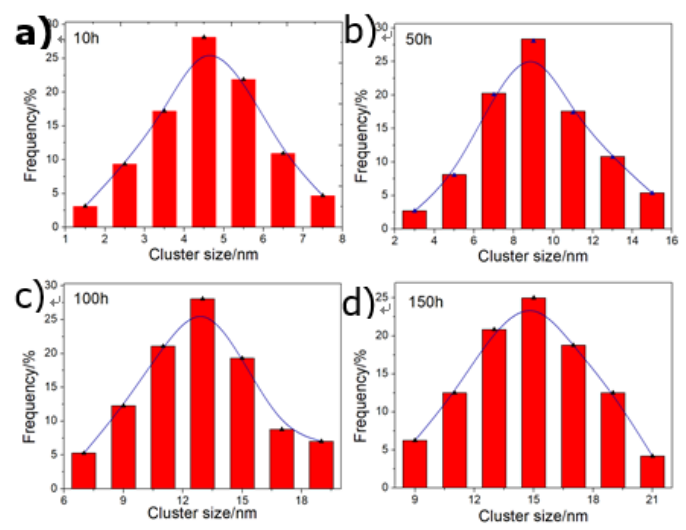

Figure 5. Cluster size statistical analysis of un-deformed specimens aged at $450{ }^{\circ} \mathrm{C}$ for: (a) $10 \mathrm{~h}$; (b) $50 \mathrm{~h}$; (c) $100 \mathrm{~h}$; (d) $150 \mathrm{~h}$.

Fig. 4 shows the TEM images of un-deformed samples of $\mathrm{Fe}-\mathrm{Cu}$ alloy aged at $450{ }^{\circ} \mathrm{C}$ for $10 \mathrm{~h}, 50 \mathrm{~h}$, $100 \mathrm{~h}$ and $150 \mathrm{~h}$. Fig. 5 shows the cluster size statistical analysis results. After aging at $450{ }^{\circ} \mathrm{C}$ for $10 \mathrm{~h}$ (Fig. 4a), the $\mathrm{Cu}$-rich clusters in un-deformed sample are pretty small. The average size is about $4.8 \mathrm{~nm}$, and the number density is pretty low. During this period, the $\mathrm{Cu}$ begins to precipitate from the matrix. After aging for $50 \mathrm{~h}$ (Fig. $4 \mathrm{~b}$ ), the average size and number density of $\mathrm{Cu}$-rich clusters increase obviously. The average size is about 9.2 $\mathrm{nm}$. After aging for $100 \mathrm{~h}$ (Fig. 4c), the size and number density of $\mathrm{Cu}$-rich clusters is pretty big. The average size is about $12.8 \mathrm{~nm}$. From Fig. 4c, it can be found that some clusters begin to bond with other clusters, which means the occurrence of over-age. After aging for $150 \mathrm{~h}$ (Fig. $4 d)$, the number density decrease. The average size of $\mathrm{Cu}$-rich clusters is about $14.6 \mathrm{~nm}$. The microstructure evolution during aging is consistent with the experimental results of Vickers hardness. At the early time of aging, the copper that solid solution in the matrix gradually precipitate and forms clusters, which hinder the movement of dislocation, resulting in the hardness increasing. As the aging continues, the $\mathrm{Cu}$ nearly precipitate from the matrix entirely and number density of $\mathrm{Cu}$-rich cluster is so large that some clusters combine with other clusters nearby, which leads to the cluster size becomes larger and the number density decrease. When 
the number density of the cluster is large, the average distance between adjacent two clusters decrease, which can hinder the movement of dislocation more effectively. After aging for about $100 \mathrm{~h}$, the $\mathrm{Cu}$ separates out from the matrix entirely, so the precipitation progress stopped and some clusters combine with other cluster nearby, resulting in the number density of clusters decrease. The average distance between adjacent two clusters becomes large, so that the dislocation can bypass or cut-through the clusters, and the hardness decrease.

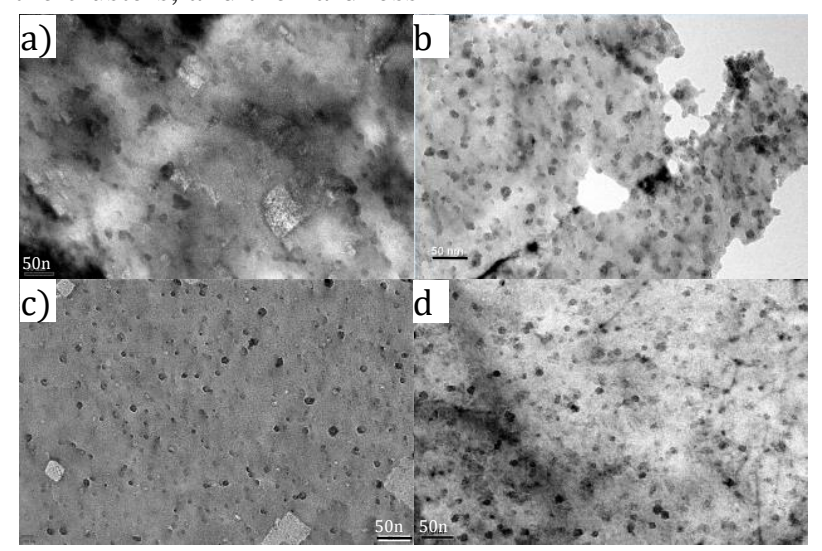

Figure 6. TEM images of un-deformed and pre-deformed samples aged at $450{ }^{\circ} \mathrm{C}$ for $150 \mathrm{~h}$ (a) un-deformed; (b) $25 \%$ deformed; (c)40\%-deformed; (d) 60\%-deformed.
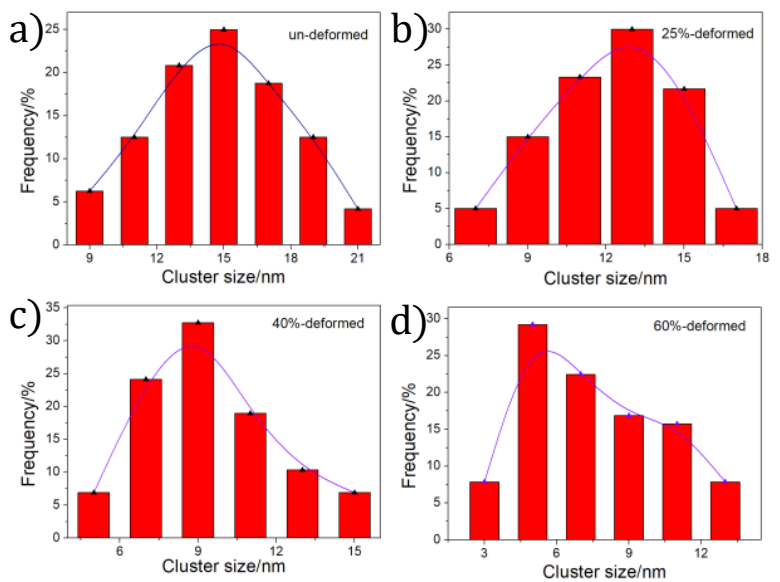

Figure 7. Cluster size statistical analysis of un-deformed and pre-deformed samples aged at $450{ }^{\circ} \mathrm{C}$ for $150 \mathrm{~h}$ (a) undeformed; (b) 25\%-deformed; (c)40\%-deformed; (d) 60\%deformed.

Fig. 6 shows the TEM images of un-deformed and $40 \%$-deformed, $60 \%$-deformed samples aged at $450{ }^{\circ} \mathrm{C}$ for $150 \mathrm{~h}$. Fig. 7 shows the cluster size statistical analysis results. It is found that the number density of $\mathrm{Cu}$-rich clusters increases with the amount of deformation obviously. The dislocation can provide nucleation sites for $\mathrm{Cu}$-rich clusters. So the higher dislocation density is induced, the more $\mathrm{Cu}$-rich clusters formed. From part 3.1, the dislocation density increase with pre-deformation, so we can get the conclusion that large pre-deformation leads to more clusters. However, the size of $\mathrm{Cu}$-rich clusters is decrease while the deformation becomes larger. The average size of $\mathrm{Cu}$ clusters for different deformation samples is $14.6 \mathrm{~nm}$ for un-deformed sample,
$12.2 \mathrm{~nm}$ for $25 \%$-deformed, $9.6 \mathrm{~nm}$ for $40 \%$-deformed and $7.5 \mathrm{~nm}$ for $60 \%$-deformed. This phenomenon can be explained as follows. The $\mathrm{Cu}$ separates out from the matrix entirely after aging at $450{ }^{\circ} \mathrm{C}$ for $150 \mathrm{~h}$. However, the $\mathrm{Cu}$ precipitate and form $\mathrm{Cu}$-rich clusters rapidly at early stages in large pre-deformed sample, resulting in the $\mathrm{Cu}$ content in the matrix decreased rapidly. So the diffusion speed of $\mathrm{Cu}$ atoms becomes slow, which limits the growth of $\mathrm{Cu}$-rich clusters. In addition, the content of $\mathrm{Cu}$ used in this work is certain, the large nuclear density means small size in the situation that $\mathrm{Cu}$ precipitate from the matrix entirely.

\section{Conclusions}

1) After aging at $450{ }^{\circ} \mathrm{C}$ for a series time, the Vickers hardness increases firstly and then reaches to peak hardness. The amount of pre-deformation influences the peak hardness time. It appears that larger predeformation promotes the evolution of clusters.

2) After aging at $450{ }^{\circ} \mathrm{C}$ for $10 \mathrm{~h}, 50 \mathrm{~h}, 100 \mathrm{~h}$ and 150 $\mathrm{h}$, the average size of $\mathrm{Cu}$-rich clusters becomes larger while the number density of $\mathrm{Cu}$-rich clusters increases first and then decreases, which is consistent with the test result of Vickers hardness.

3) With the amount of pre-deformation increase, the size of $\mathrm{Cu}$-rich clusters becomes smaller and the number density of $\mathrm{Cu}$-rich clusters increase after aging at $450{ }^{\circ} \mathrm{C}$ for $150 \mathrm{~h}$.

\section{Acknowledgements}

This research was partly supported by Shenzhen Science and Technology Innovation Committee (Fund \# JCYJ20170307153239266) and a research program of Ministry of Science and Technology of the People's Republic of China (Fund \# 2017YFB0305300). The experiment was done with the support of Joint Laboratory of Nuclear Materials and Service Safety.

\section{References}

1. E.D. Eason, G.R. Odette, R.K. Nanstad, T. Yamamoto, J NUCL MATER. 433, 240 (2013)

2. R.G. Carter, N. Soneda, K. Dohi, J.M. Hyde, C.A. English, W.L. Server, J NUCL MATER. 298, 211 (2001)

3. F. Bergner, F. Gillemot, M. Hernández-Mayoral, M. Serrano, G. Török, A. Ulbricht, E. Altstadt, J NUCL MATER. 461, 37 (2015)

4. N. Soneda, Irradiation embrittlement of reactor pressure vessels (RPVs) in nuclear power plants Elsevier. (2014)

5. L. Liu, K. Nishida, K. Dohi, A. Nomoto, N. Soneda, K. Murakami, Z.C. Li, D.Y. Chen, N. Sekimura, J NUCL SCI TECHNOL. 53, 1546 (2016)

6. T. Toyama, Y. Nagai, Z. Tang, M. Hasegawa, A. Almazouzi, E. van Walle, R. Gerard, ACTA MATER. 55, 6852 (2007) 
7. T. Takeuchi, A. Kuramoto, J. Kameda, T. Toyama, Y. Nagai, M. Hasegawa, T. Ohkubo, T. Yoshiie, Y. Nishiyama, K. Onizawa, J NUCL MATER. 402, 93 (2010)

8. H. Takamizawa, H. Itoh, Y. Nishiyama, J NUCL MATER. 479, 533 (2016)

9. G.R. Odette, G.E. Lucas, JOM. 53, 18 (2001)

10. M.K. Miller, B.D. Wirth, G.R. Odette, Mater. Sci. Eng., A. 353, 133 (2003)

11. L. Liu, K. Murakami1, K. Dohi, K. Nishida, A. Nomoto, N. Soneda, Z.C. Li, N. Sekimura, J Adv Maint. 7, 117 (2015)

12. G.K. Williamson, W.H. Hall, ACTA METALL. 1, $22(1953)$

13. J. Kočík, E. Keilova, J. Čížek, I. Procházkab, J NUCL MATER. 303, 52 (2002)

14. W.H. Zhou, H. Guo, Z.J. Xie, C.J. Shang, R.D.K Misra, MATER DESIGN. 63, 42 (2014)

15. C.J. Bettles, M.A. Gibson, K. Venkatesan, SCRIPTA MATER. 51, 193 (2004)

16. M. Abdel-Rahman, Int. J. New. Hor. Phys. 4, 43 (2017)

17. G. Stechauner, E. Kozeschnik, J MATER ENG PERFORM. 23, 1576 (2014)

18. R. Gomez-Ramirez, G.M. Pound, METALL MATER TRANS. 4, 1563 (1973)

19. K. Soeno, J JPN I MET. 11, 185 (1970)

20. D.G. Park, M.B. Kishore, D.H. Lee, J.Y. Kim, L.J. Jacobs, G. Vertesy, D. Son, NDT\&E INT. 89, 14 (2017) 